\title{
Fatigue of Welded Magnesium Alloy Joints*1
}

\author{
Masato Tsujikawa ${ }^{1}$, Hidetoshi Somekawa ${ }^{1, * 2}$, Kenji Higashi ${ }^{1}$, Hayato Iwasaki ${ }^{2}$, \\ Takeshi Hasegawa ${ }^{2}$ and Akiyoshi Mizuta ${ }^{2}$ \\ ${ }^{1}$ School of Engineering, Osaka Prefecture University, Sakai 599-8531, Japan \\ ${ }^{2}$ Technical Institute, Kawasaki Heavy Industries, LTD., Akashi 673-8666, Japan
}

Fatigue tests were carried out on welded joints of commercial AZ31 alloy and AZ61 alloy in air as welded surface condition. Alloys were extruded or rolled to a plate shape. Pairs of the same type of alloy plates were butt-welded by tungsten inert gas (TIG) welding or friction stir welding (FSW). All welded joints except FSW-ed AZ61 have joint efficiency of around 90\% for static tensile strength. Extruded AZ31 alloy joints by TIG or FSW showed fatigue joint efficiency of about $80 \%$. However, fatigue joint efficiencies for other joints were at around $60 \%$. Fracture surfaces showed brittle fatigue crack propagation; moreover, the directions of crack propagation were influenced remarkably by the microstructures.

(Received November 6, 2003; Accepted January 16, 2004)

Keywords: magnesium alloy, tungsten inert gas arc welding, friction stir welding, fatigue strength, crack propagation

\section{Introduction}

Magnesium alloys have attracted special attention of researchers working in transportation industries because they are the best lightweight structural materials with a relatively high-strength to weight ratio and excellent technological properties. Enhancement of structural application of such a structural material depends on the ability of construction by welding. The welding of magnesium alloys has been investigated widely. Results indicate that FSW (friction stir welding) and TIG (tungsten inert gas arc welding) are successful welding methods for magnesium alloys and aluminum alloys. ${ }^{1-4)}$ Reliability is their salient attribute, especially for use in the transportation industry. Therefore, the clarification of fatigue properties must precede application of joining by welding. ${ }^{5 \text { ) }}$

This study investigated the factors which affect the fatigue strength of the welded commercial magnesium alloy joints as welded surface. Investigated alloys were extruded or rolled AZ31 and AZ61. The welding processes used in this investigation were TIG and FSW. Joint efficiencies $\left(\sigma_{\text {joint }} / \sigma_{\text {base metal }}\right.$, where $\sigma_{\text {joint }}$ and $\sigma_{\text {base metal }}$ represent strengths of the joint and base metal) for static tensile strength and fatigue strength were measured; SEM (scanning electron microscopy) observed initiation points of fatigue cracks and the paths of crack propagation.

\section{Experimental Procedure}

\subsection{Magnesium alloy plates and welding process}

Table 1 shows chemical compositions of tested plates. Hot-extruded AZ31, AZ61, and hot-rolled AZ31 plates were $2 \mathrm{~mm}$ in thickness; another hot-rolled AZ61 plate was $4 \mathrm{~mm}$ thick.

Welded joints were made of two plates of the same type. Extruded plates and rolled plates were prepared with $1000 \mathrm{~mm}$ length (parallel to extruding or rolling direction) and $100 \mathrm{~mm}$ width. For rolled plates, plates of inverse aspect ratio were also prepared with $100 \mathrm{~mm}$ length (parallel to rolling direction) and $240 \mathrm{~mm}$ width. Two plates were welded together at their long side. The welding line length was $1000 \mathrm{~mm}$ parallel to the extrusion or rolling direction (we call specimens cut from these joints as T specimens), and $240 \mathrm{~mm}$ for perpendicular to the rolling direction ( $\mathrm{L}$ specimen).

Plates were welded by TIG with filler wire of the same grade as plates to make butt joints. FSW was used for extruded AZ31 and AZ61 plates. All specimens were inspected by X-ray radiography; then only sound specimens were used for static tensile and fatigue tests. The total pass rate of radiograph inspection was $89 \%$. Most defects were pores and blow holes. No FSWed joints failed the Xray inspection.

\subsection{Fatigue test}

Tensile fatigue specimens were cut from welded plates as the weld line was across the tensile axis at the center of the

Table 1 Chemical compositions of samples (mass\%).

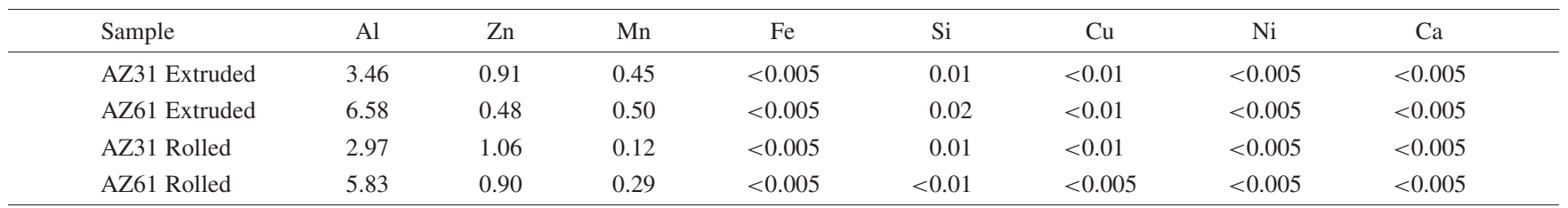

\footnotetext{
*1 This Paper was Presented at the Autumn Meeting of the Japan Institute of

Metals, Held in Sapporo, on October 12, 2003

${ }^{* 2}$ Graduate Student, Osaka Prefecture University
} 
specimen. Fatigue tests were performed on hydraulic servo pulser type fatigue machines at $R=\sigma_{\min } / \sigma_{\max }=0.1$ in air at room temperature. The pulse shape was a sinusoidal wave; the cycling frequency was $10 \mathrm{~Hz}$.

\section{Results and Discussion}

\subsection{Features of welding}

Figure 1 shows cross sectional views of joints made of extruded alloys as examples. The TIG-ed joints had sufficient fusion and a uniform bead line throughout welding length with no overlaps or undercuts. The FSW-ed joints have geometrically smoother section than TIG-ed joints. However, the center of welded line shows slight reduction of thickness. Typical FSW nugget patterns can be observed, especially in the AZ61 joint.

Figure 2 shows microstructures of AZ31 joints. In the TIGed joint of extruded AZ31 alloy, the base metal has a grain size of about $35 \mu \mathrm{m}$; the grains of weld metal are slightly greater than base metal grains, and the grains of HAZ are largest. Such a grain size distribution is shown more clearly in rolled alloy joint. FSW-ed AZ31 joint has remarkably refined weld metal (nugget) and HAZ (or thermo-mechanically affected zone ${ }^{6)}$ ).

Figure 3 shows microstructures of AZ61 joints. Similar

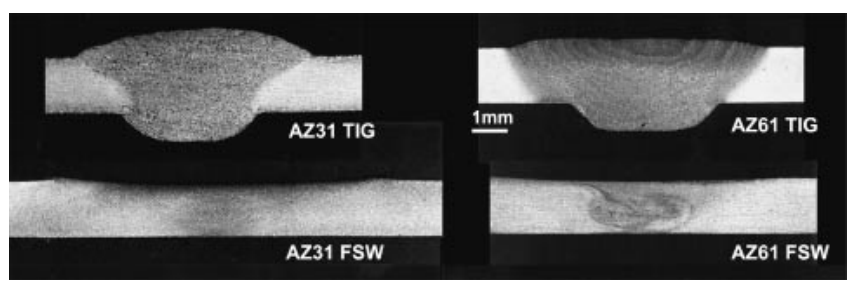

Fig. 1 Cross section view of welded joints.

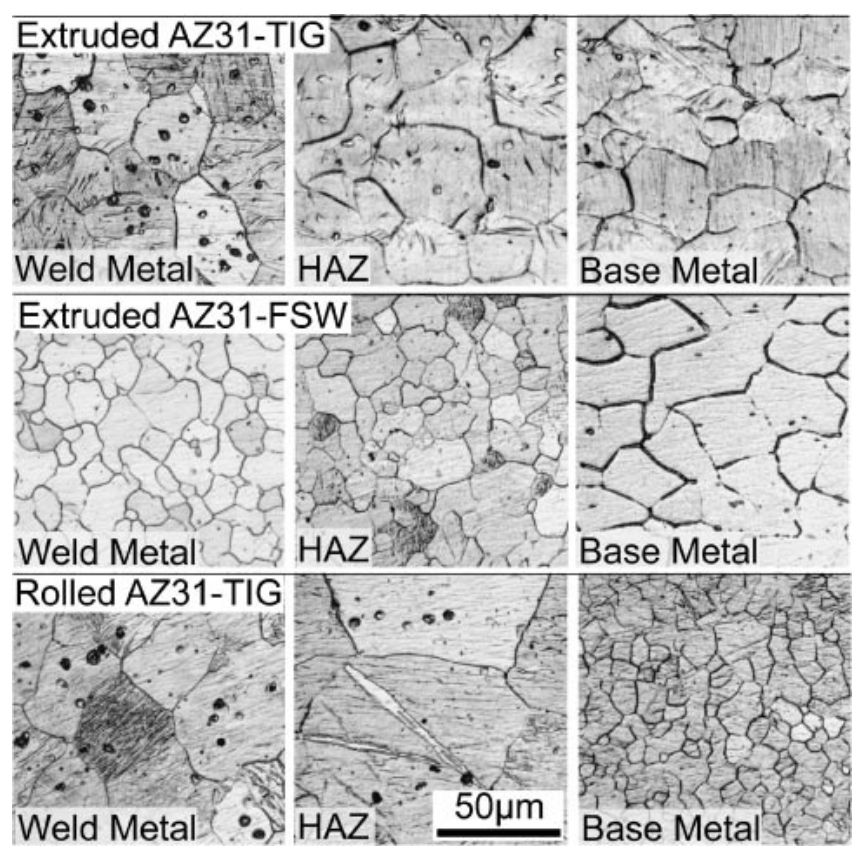

Fig. 2 Microstructures of welded joints of AZ31.

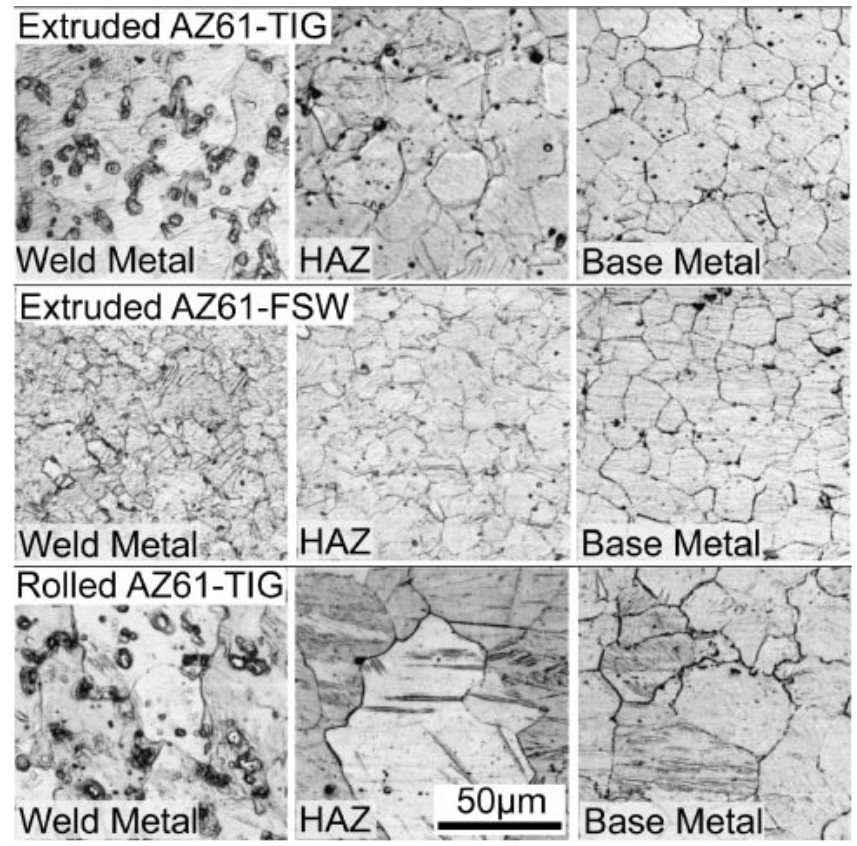

Fig. 3 Microstructures of welded joints of AZ61.

grain size distribution as AZ31 can be observed in AZ61. There are some etch pits induced by small precipitated inclusions at weld metal and at HAZ of TIG-ed joint as shown in Figs. 2 and 3. These inclusions are thought to be metallic compound as the precipitated $\mathrm{Al}_{12} \mathrm{Mg}_{17}$. The volume fraction of the inclusions was measured as about $1.2 \mathrm{vol} \%$ in the AZ weld metal and about 3 vol\% in the AZ61weld metal.

\subsection{Hardness and static tensile properties}

Figure 4 shows hardness profiles of the joints. Hardness of the base metals was 54 and $66 \mathrm{HV} 30 \mathrm{~N}$ for extruded AZ31 and AZ61, 55 and 58HV30N for rolled AZ31 and AZ61. The FSW-ed joint of extruded AZ61 shows relatively uniform distribution; ${ }^{7)}$ the FSW-ed AZ31 also has moderate scattering of hardness at the nugget. ${ }^{4}$ However, TIG-ed joints have large scattering of hardness value at weld metals. Especially, hardness of the extruded AZ61 joint was low at HAZ.

Table 2 lists static tensile properties of the base metals and the joints, and fatigue strength that will be described later.

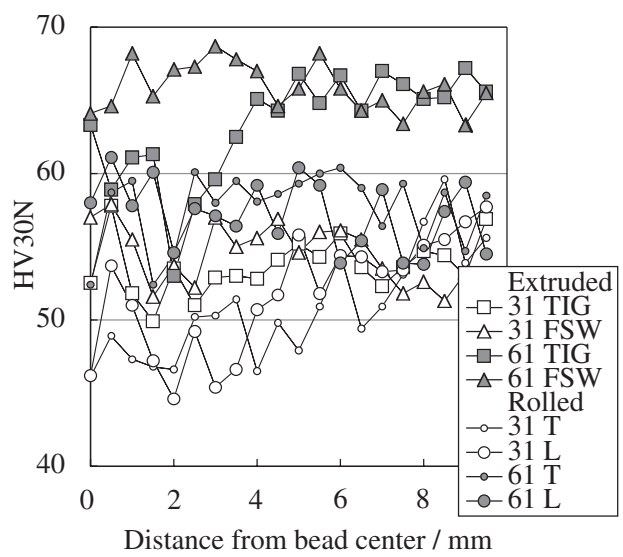

Fig. 4 Hardness profiles of joints. 
Table 2 Results of static tensile test and fatigue test.

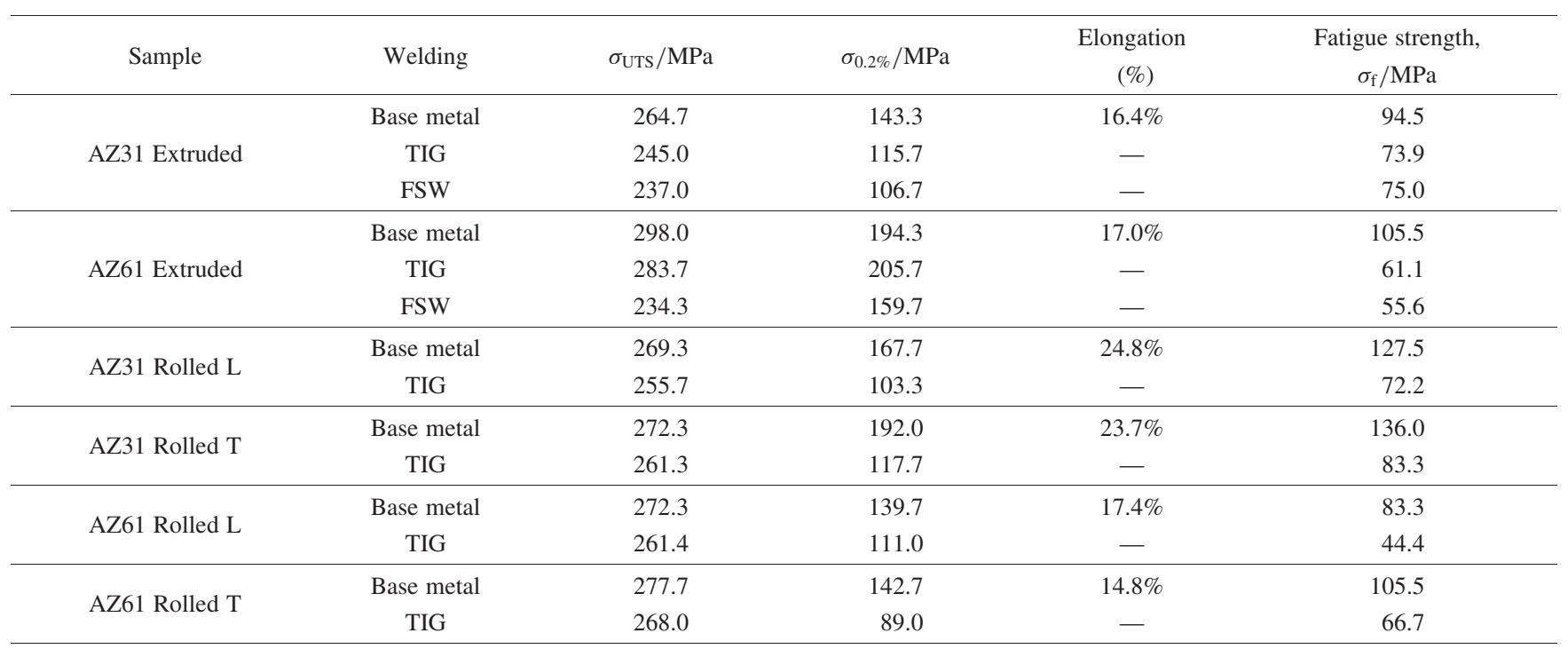

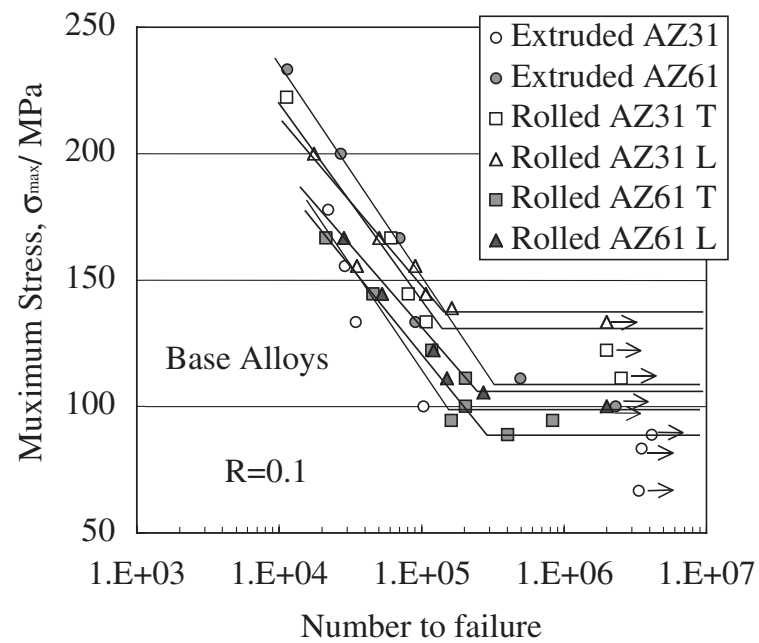

Fig. 5 S-N curves of magnesium alloy base metals.

Elongation data for joints were not evaluated because of the brittle fracture at the toe (junction between the weld face and the base metal).

\subsection{Fatigue test results}

Figure 5 shows the S-N curves of base metals. Fatigue limits were clearly observed on their curves. ${ }^{8)}$ Figures 6 and 7 show the S-N curves of joints made of extruded alloys and rolled alloys. Curves of joints were more inclined than those of the base metals. That is, an increase in stress amplitude shortened the fatigue life more severely for joints than for base metals.

Fatigue strength values of extruded alloy base metals are 94.5 MPa and 105.5 MPa for AZ31 and AZ61, as shown in Table 2. The values of joints were much lower than those of base metals, in spite of the increase of thickness at the bead line.

Figure 8 shows joint efficiencies for static tensile strength (a) and for fatigue strength (b). The joint efficiencies of static strength were over 90\%, except for FSW-ed joints. ${ }^{9)}$ However, efficiencies for fatigue strength were around $60 \%$,

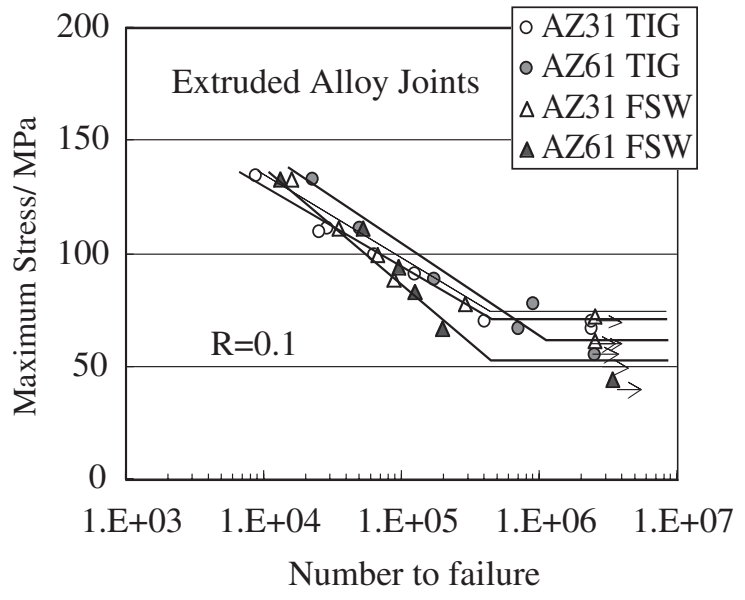

Fig. 6 S-N curves of butt-welded extruded plates.

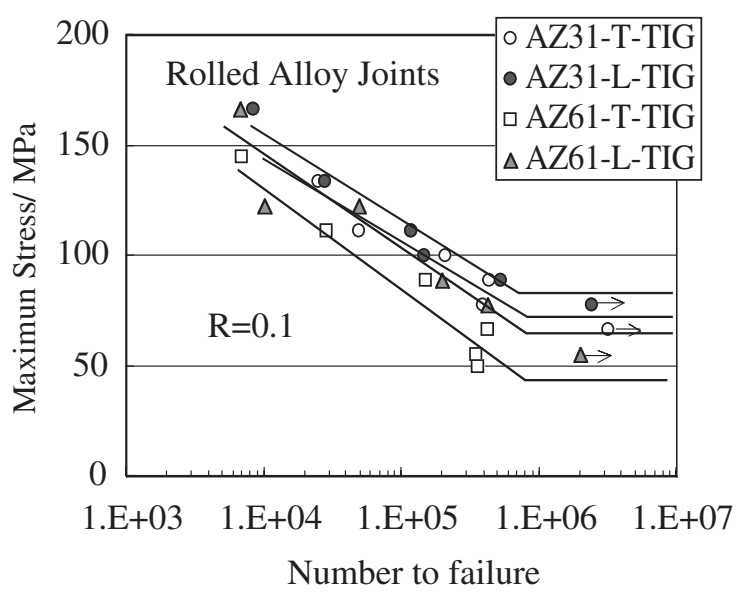

Fig. 7 S-N curves of butt-welded rolled plates.

except for joints of extruded AZ31. These extruded AZ31 joints have efficiencies around $80 \%$, regardless of the welding process. 


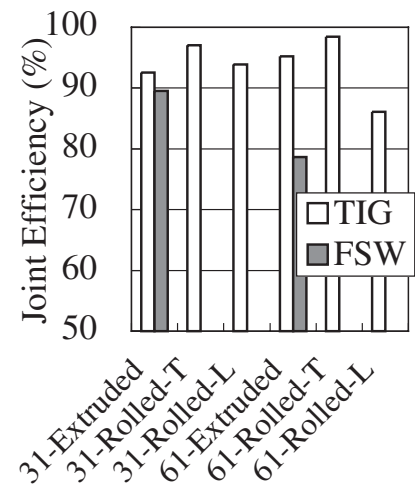

(a) Static Strength

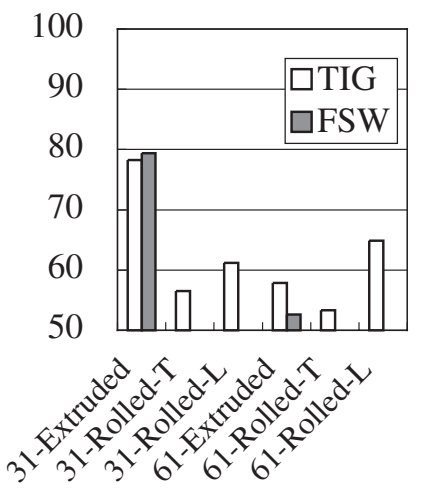

(b) Fatigue Strength
Fig. 8 Joint efficiencies for static tensile strength and fatigue strength.

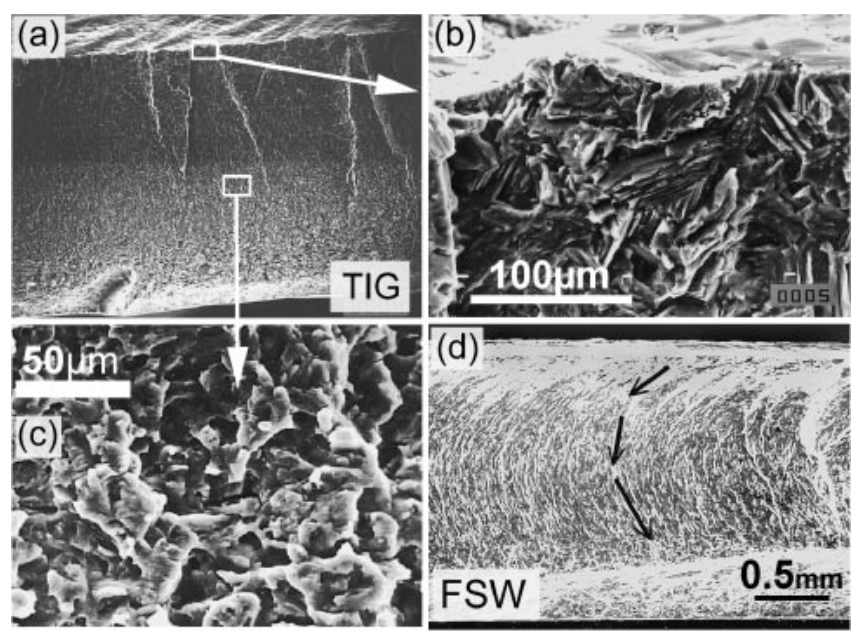

Fig. 9 Typical fatigue fracture surfaces of welded AZ31 alloy joints.

\subsection{Fracture surfaces}

Figure 9 shows SEM observation of the fatigue fracture surfaces. As shown in (a), fatigue cracks in TIG-ed specimens always initiated at the toe of bead line. Moreover, $83 \%$ of the fatigue cracks initiated at the backside toes. The cracks propagated through weld metal vertically to the loading axis macroscopically.

These initiation points, or lines, are stress concentrated positions. In addition, they are the most severe heat-affected position of large grain size. Rethmeier and Wiesner ${ }^{5)}$ reported a 50\% increase in fatigue strength by work-off of the welding bead at the magnesium alloy joint of metal inert gas (MIG) welding. Deterioration of structure at HAZ and high notch sensitivity of the magnesium alloys are complementary reasons for the low joint efficiency of fatigue.

In FSW-ed joints, fatigue cracks always initiated at the center of weld line, where the thickness is the smallest. The cracks in FSW-ed specimens also propagated the vertical plane against loading axis, but the growth of the cracks swerved from the straightforward manner to make a detour. Fatigue cracks seem to propagate as indicated in Fig. 9(d). It appears that the basal plane textures and flow patterns in friction stir welding in magnesium alloys ${ }^{10,11)}$ affected fatigue crack propagation.
Figure 9(b) shows details of the crack initiation position of a TIG welded specimen. The fracture surface is in weld metal. The weld metal structure comprises equiaxed grains ${ }^{12}$ ) which have random crystal orientations. We can see stripe patterns as a characteristic feature of magnesium fatigue. ${ }^{13)}$ Microscopic propagation of fatigue cracks at magnesium alloy is greatly influenced with crystallographic orientation of structures. Brittle striation patterns were also observed at the final stage of fatigue crack propagation toward main crack direction, ${ }^{14)}$ as in Fig. 9(c). These observations clarified complex propagation of fatigue cracks in magnesium welded joints.

\section{Conclusions}

(1) Joint efficiencies for static tensile strength are over $90 \%$ for tungsten inert gas welded AZ31 and AZ61 alloy plates. Efficiencies for friction stir welded joints of extruded AZ31 and AZ61 alloys were 89\%, and 78\%, respectively.

(2) Howewver, joint efficiencies for fatigue strength were around 60\%, except for extruded AZ31 alloy joints which have efficiencies around $80 \%$.

(3) Large main crack detours were observed at friction stir welded specimens. They seemed to follow the basal plane texture. In addition, the microscopic direction of crack propagation is affected by grain orientation in fusion-welded joints.

\section{Acknowledgements}

This work was supported by New Energy and Industrial Technology Development Organization (NEDO No. 140509006).

\section{REFERENCES}

1) J. Kaneko, T. Asahina, M. Sugamata, Y. Nishikawa and H. Takada: J. Japan Inst. Metals 64 (2000) 1239-1244.

2) A. Munitz, C. Cotler, A. Stern and G. Kohn: Mater. Sci. Eng. A 302 (2001) 68-73.

3) Z. Sun, D. Pan and J. Wei: Sci. Technol. Weld. Joining 7 (2002) 343351.

4) W. B. Lee, J. W. Kim, Y. M. Yeon and S. B. Jung: Mater. Trans. 44 (2003) 917-923.

5) M. Rethmeier and S. Wiesner: Z. Metall. 92 (2001) 281-285.

6) W. B. Lee, Y. M. Yeon and S. B. Jung: Mater. Sci. Technol. 19 (2003) 785-790.

7) T. Asahina and H. Tokisue: Mater. Trans. 42 (2001) 2345-2353.

8) T. Fuji, N. Fuyama and C. Masuda: Magnesium Alloys 2003, Mater. Sci. Forum 419-422 (2003) 109-114.

9) S. F. Su, J. C. Huang, H. K. Lin and N. J. Ho: Metall. Mater. Trans. A 33 (2002) 1461-1473.

10) S. H. C. Park, Y. S. Sato and H. Kokawa: Metall. Mater. Trans. A 34A (2003) 987-994.

11) S. H. C. Park, Y. S. Sato and H. Kokawa: Scr. Mater. 49 (2003) 161166.

12) J. A. Esparza, W. C. Davis and L. E. Murr: J. Mater. Sci. 38 (2003) 941-952.

13) S. Ando, K. Saruwatari, T. Hori and H. Tonda: J. Japan Inst. Metals 67 (2003) 247-251.

14) T. S. Shih, W. S. Liu and Y. J. Chen: Mater. Sci. Eng. A 325 (2002) $152-162$. 